\title{
Reliability assessment for electrical power generation system based on advanced Markov process combined with blocks diagram
}

\author{
A. A. Tawfiq', M. Osama abed el-Raouf ${ }^{2}$, A. A. El-Gawad ${ }^{3}$, M. A. Farahat ${ }^{4}$ \\ ${ }^{1}$ Electrical Power and Machines Department, the Public Authority for Applied Education and Training, \\ Vocational Training Institute, Kuwait \\ ${ }^{2}$ Building Physics and Environmental Research Institute, Housing, and Building National Research Center, Egypt \\ ${ }^{3}$ Electrical Power and Machines Department, Vice Dean of Faculty of Computer and Information, Zagazig University, \\ Zagazig, Egypt \\ ${ }^{4}$ Electrical Power and Machines Department, Faculty of Engineering, Zagazig University, Zagazig, Egypt
}

\begin{abstract}
Article Info
Article history:

Received Oct 16, 2020

Revised Mar 10, 2021

Accepted Mar 21, 2021

\section{Keywords:}

Block diagrams

Electrical power system

Markov process

Probability failure states

Reliability assessment

ABSTRACT

This paper presents the power generation system reliability assessment using an advanced Markov process combined with blocks diagram technique. The effectiveness of the suggested methodology is based on HL-I of IEEE_EPS_24_bus. The proposed method achieved the generation reliability and availability of an electrical power system using the Markov chain which based on the operational transition from state to state which represented in matrix. The proposed methodology has been presented for reliability performance evaluation of IEEE_EPS_24_bus. MATLAB code is developed using Markov chain construction. The transition between probability states is represented using changing the failure and repair rates. The reduced number of generation system are used with Markov process to assess the availability, unavailability, and reliability for the generation system. Additionally, the proposed technique calculates the frequency, time duration of states, the probability of generation capacity state which get out of service or remained in service for each state of failure, and reliability indices. A considerable improvement in reliability indices is found with using blocks diagram technique which is used to reduce the infinity number of transition states and assess the system reliability. The proposed technique succeeded at achieving accurate and faster reliability for the power system.
\end{abstract}

This is an open access article under the CC BY-SA license.

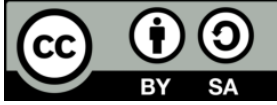

\section{Corresponding Author:}

Aiman Abdel-Kader Tawfiq

Vocational Training Institute

The Public Authority for Applied Education and Training

Adailiyah, Kuwait

Email: aimantowfic@yahoo.com

$\begin{array}{ll}\text { LIST OF APPRIVIATIONS } \\ \text { A } & \text { Availability } \\ \text { FFSi } & \text { Failure frequency of i state } \\ \text { IEEE_EPS_24_bus } & \text { IEEE electrical power system with } 24 \text { buses } \\ \text { LOLE } & \text { Loss of load expectation } \\ \text { LOLP } & \text { Loss of load probability } \\ \text { MDS }_{\mathrm{i}} & \text { Mean duration of states } \\ \mathrm{P} & \text { The probability matrix } \\ \mathrm{Q}_{\mathrm{i}} & \text { Unavailability of component i }\end{array}$




$\begin{array}{ll}\mathrm{Q}_{\mathrm{p}} & \text { Total unavailability of parallel components } \\ \mathrm{RDS}_{\mathrm{i}} & \text { Rate of departure of } \mathrm{i} \text { state } \\ \mathrm{R}_{\mathrm{par}} & \text { Total reliability of parallel components } \\ \mathrm{R}_{\text {ser }} & \text { Total reliability of series components } \\ \mathrm{R}_{\text {sys }} & \text { Ttotal system reliability } \\ \mathrm{T} & \text { The time period } \\ \lambda \mathrm{p} & \text { Total failure rate of parallel components } \\ \lambda_{\text {ser }} & \text { Total failure rate of series components } \\ \mu & \text { The repair rate }\end{array}$

\section{INTRODUCTION}

The reliability of the generation system is defined as the ability of generation system to supply the power to consumers for a determined time's period without outages. The reliability is evaluated to determine the ability of components to achieve consumer satisfaction. The bulk electric power system reliability assessment consists of three steps, selection of system states, evaluation of adequacy of states and computation of reliability indices [1]. The main important factors affect power system reliability are the system security and the system adequacy. The system security is associated with the system response to fault interruptions of the system while the system adequacy is related to system load conditions and existence of sufficient facilities to meet the needs of consumers [1]. The analysis of system adequacy assessment of any electrical power system can be divided into three principal functional zones namely hierarchical level (1), hierarchical level (2), and, hierarchical level (3) as shown in Figure 1 [1]. In electrical power systems, two approaches are used to assess the system reliability, one of them is based on the components historical and the other is based on predictive assessment [2].

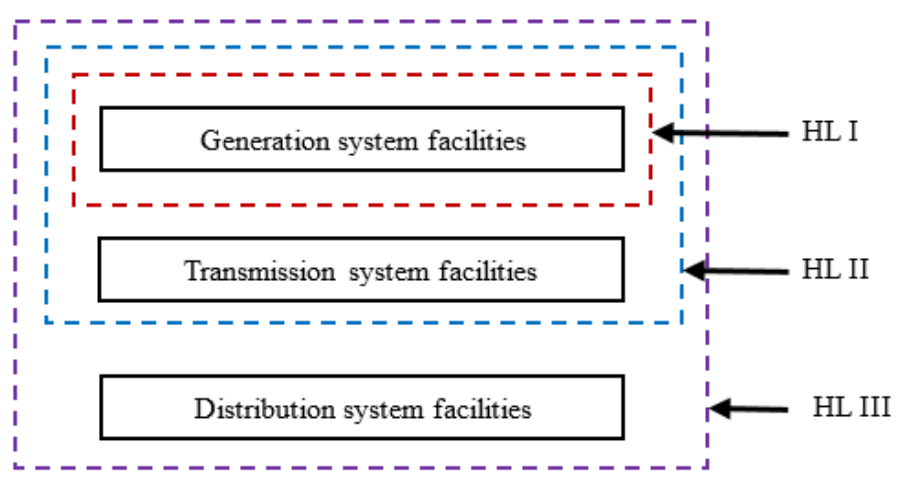

Figure 1. Electrical power system hierarchical levels diagram

In the past few years, researchers focused on probability and reliability assessment of the electrical power system in case of generation, transmission, and distribution by using different techniques to achieve the aims. Boussahoua and Elmaouhab [3], presented an assessment of the electrical power transmission system reliability by using block diagram and graph theories for IEEE 9 bus system. The results show that, the effect of the classification of nodes according to their reliability, the effect of disconnections of nodes and transmission branches on reliability. Babu et al. [4], proposed the reliability assessment for a composite generation system for RTS_3_bus, RTS_6_bus, and RTS_24_bus systems using probability performance index with critical contingencies. The results show the effectiveness of this technique to identify the weak points for systems' developing reinforcement ways. Abdulkarim et al. [5], used block diagram technique to assess the configuration of microgrid system and studied the impact of renewable generation's components on system reliability. The results show that, the reliability indices decreased in case of using diesel generator. Khare et al. [6], proposed the reliability evaluation for hybrid renewable generation system using fault tree technique. Shalash et al. [7], evaluated the power system generation indices using multi agent model and compared the results with that resulted by the analytical approach. The results show the effectiveness of technique to decide increasing or decreasing capacity and loads. Adefarati and Bansal [8], focused on the economic side and environmental benefits of system reliability assessment with renewable generators. The results show the advantages of using the green buildings and renewable energies in microgrid on reliability. Bourezg and Meglouli [9], used $\mathrm{C} / \mathrm{C}++$ to create disjoint sum of product algorithm for evaluating the power distribution system to avoid the disadvantage of Monte Carlo technique. Kunaifi and Reinders [10], proposed 
the reliability evaluation for electric supply Indonesia system by collecting the surveys and measurement the electric parameters from consumer sides. The reliability evaluation for both distribution system which has low voltage versus the transmission system which has high voltage presented in [11], [12]. Almuhamaini and Al-Sakkaf [13], proposed the reliability evaluation of distribution system in microgrid without installed distributed generators and with installed distributed generators including the calculation of the reliability indices of the system. The results show the accurate and effectiveness of used method for reliability evaluation with voltage violations Liu and Singh. [14], presented reliability evaluation for composite power system reliability and taken into account the effect of weather. The DC_OPF, minimal cut set, and Markov process are used to calculate the system reliability indices and the bounds of reliability indices. Thompson et al. [15] proposed reliability evaluation and cost of HVDC transmission interconnection feeders with using MMC converter using Monte Carlo simulation method. Ren et al. [16], proposed the reliability evaluation of nine microgrid system taking into account the insufficient transmission capacity of the system using Bayesian network based unified modeling (BNBUM) method. The results show the important role of using the energy storage and energy dispatch strategy on reliability evaluation. Raghuwanshi and Arya [17] used Markov and frequency duration methods to assess the reliability indices of hybrid energy system including diesel, PV, and battery. Pham et al. [18] presented the reliability evaluation for microgrid system with multiple battery storage under various dynamic operation cases using Markov technique.

The proposed method analyzes the reliability of electrical power system generation based on the failure and repair rates of each unit of generators. There are two main categories of electrical system reliability assessment techniques, one of them is simulation or Monte Carlo technique and the other is analytical model. Simulation approaches estimate the electrical indicators by simulating actual electrical system and random behavior of the system [19]. Analytical approaches represent the electrical system by mathematical model and assess the indicators or reliability from this model by using mathematical analysis. There are more analytical techniques used to compute the reliability of electrical power system such as block diagram, Markov process, fault tree analysis, event tree analysis, minimal cut set, minimal tie method, and path tracing method [20].

This paper presents the reliability assessment of generation for IEEE_EPS_24_bus system using an advanced Markov process and blocks diagram techniques. The proposed methodology achieved the reliability evaluation using the best technique for probabilities studying, namely Markov chain process. Also assessed the reliability indices loss of load probability (LOLP) and loss of load expectation (LOLE). The Markov process based on the transition between probability states as explained in section 3 . The challenge in the proposed method is the infinity number of failures probability states due to the large number of generation units. The method overcome to the challenge by using the block diagram technique to reduce the number of elements as discussed in section 2. The proposed study analyzes the results and calculates the frequency, mean duration of failure states for system, the maximum and minimum frequency and duration of failure probability state. The probability of generation capacity state which remained in service and kept out of service for each probability state of failure, system reliability assessment, and system reliability indices are discussed in section 4.

\section{RESEARCH METHOD}

\subsection{Block diagram}

The block diagram method is used to assess the total system reliability and analyze the probability of system's failure [21]. It can be achieved using representing the system and its components by graphical representation with dividing the system to smallest groups. The interconnected group may be in series, parallel, series parallel, or parallel series connections. All of these combinations are used to achieve the solution.

\subsubsection{Series combination}

The system reliability may be consisting of interconnected group of exponential function which is characterized by failure rate. The failure of any component causes the whole system to fail. The system shown in Figure 2 consists of $\mathrm{n}$ components in series connection. each component has failure and repair rate.

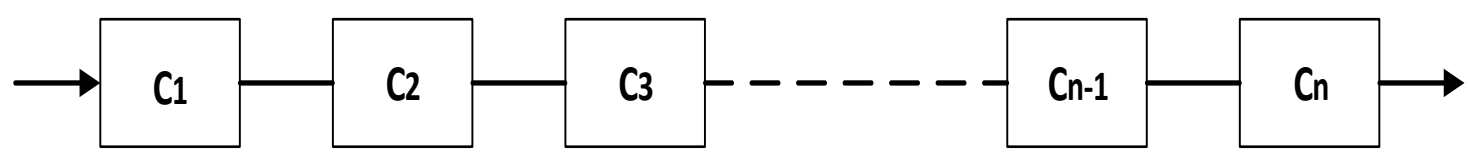

Figure 2. Block diagram consists of $\mathrm{n}$ components connected in series 
The system reliability and failure rate for series components are calculated as shown in (1), (2), and (3) [20], [22], [23].

$$
\begin{aligned}
& \mathrm{R}_{\mathrm{sys}}(\mathrm{t})=e^{-\lambda t} \\
& \mathrm{R}_{\mathrm{ser}}=\prod_{i=1}^{n} R i \\
& \lambda_{\mathrm{ser}}=\sum_{i=1}^{n} \lambda \mathrm{i}
\end{aligned}
$$

\subsubsection{Parallel combination}

The system shown in Figure 3 consists of $\mathrm{n}$ components in parallel connection. each component has failure and repair rates. The failure of any component doesn't cause the whole system to fail while the failure of all components causes the whole system to fail [5].

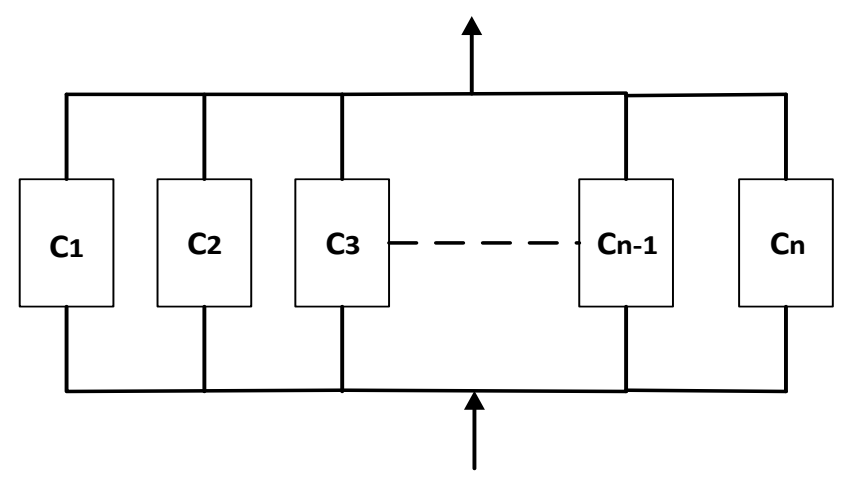

Figure 3. Block diagram consists n components connected in parallel

The system reliability, unavailability, availability, and failure rate for parallel components are calculated in (4)-(7) [5].

$$
\begin{aligned}
& \mathrm{R}_{\mathrm{par}}=1-\prod_{\mathrm{i}=1}^{\mathrm{n}}(1-\mathrm{Ri}) \\
& \mathrm{Q}_{\mathrm{p}}=\prod_{\mathrm{i}=1}^{\mathrm{n}} \mathrm{Q}_{\mathrm{i}} \\
& \mathrm{R}_{\mathrm{par}}=\mathrm{A}=1-\prod_{\mathrm{i}=1}^{\mathrm{n}} \mathrm{Q}_{\mathrm{i}} \\
& \frac{1}{\lambda \mathrm{p}}=\left[\frac{1}{\lambda 1}+\frac{1}{\lambda 2}+\ldots . .+\frac{1}{\lambda \mathrm{n}}\right]-\left[\frac{1}{\lambda 1+\lambda 2}+\frac{1}{\lambda 1+\lambda 3}+\ldots . .+\frac{1}{\lambda 1+\lambda \mathrm{n}}\right]+ \\
& {\left[\frac{1}{\lambda 1+\lambda 2+\lambda 3}+\frac{1}{\lambda 1+\lambda 2+\lambda 4}+\ldots . .+\frac{1}{\lambda 1+\ldots . .+\lambda \mathrm{n}}\right]-\ldots \ldots \ldots \ldots . .+\left[(-1)^{\mathrm{n}+1}\left(\frac{1}{\sum_{1}^{\mathrm{n}} \lambda \mathrm{n}}\right)\right]}
\end{aligned}
$$

\subsection{Markov process}

The analytical model presents clearly representation of all the states of a system and also the transition between these states [3], [24]. Three steps are required to achieve the analytical Markov model which are named zero one matrix construction, transition Markov matrix, and solving the Markov equation. To calculate the probability of the system, analytical Markov model must be established in three steps.

\subsubsection{Zero one Markov matrix}

Suppose an electrical system has three generator components G1, G2, and G3 as shown in Figure 4, therefore there will be $2^{3}=8$ states. The electrical component states are On and Off or 0 and 1 , respectively. The zero means no change in the case and the connection is On. The one means the state changed and the connection is Off.

The state probabilities are listed in Table 1, zero one Markov matrix inferred from the state probabilities as shown in the Table 1. From the table, it is noticed that the three components are operates in case of state 1, first component fails and other components operate in case of state 2, second component fails and other components operate in case of state 3, first and second components fail and third one operates in 
case of state 4 , third component fails and other components operate in case of state 5, first and third components fail and second one operates in case of state 6 , second and third components fail and first one operates in case of state 7, and Three components fail in case of state 8. After states determination, the zero one matrix have constructed from the list of states by transition only from On state to Off state for each case. The dimensions of zero one matrix are equal to $i$ and $j$ which are equal to 2 and 3 , respectively.

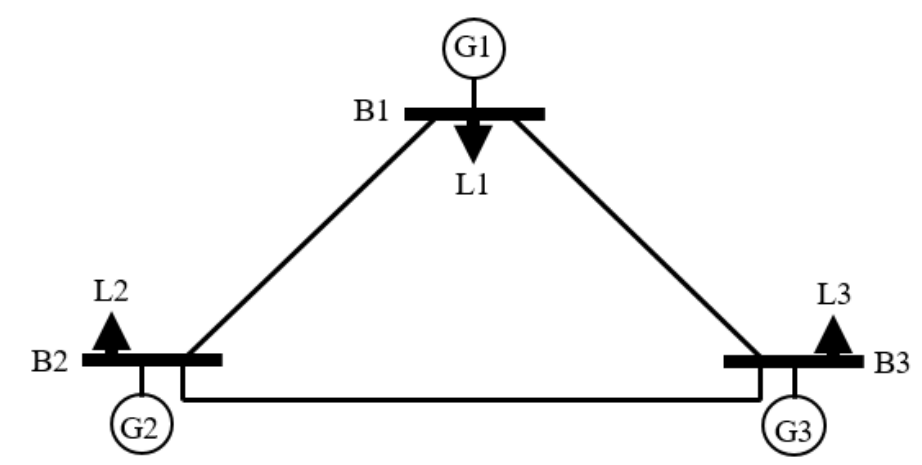

Figure 4. Three generation components system

Table 1. List of states for three system components

\begin{tabular}{ccccc}
\hline States & Comp. (1) & Comp. (2) & Comp. (3) & Describe \\
\hline State 1 & 0 & 0 & 0 & Three components operate \\
State 2 & 1 & 0 & 0 & $1^{\text {st }}$ comp. failure and other comps operate \\
State 3 & 0 & 1 & 0 & $2^{\text {nd }}$ comp failure and other comps operate \\
State 4 & 1 & 1 & 0 & $1^{\text {st }}$ and $2^{\text {nd }}$ comps failure and $3^{\text {rd }}$ one operates \\
State 5 & 0 & 0 & 1 & $3^{\text {rd }}$ comp. failure and other comps operate \\
State 6 & 1 & 0 & 1 & $1^{\text {st }}$ and $3^{\text {rd }}$ comps failed and $2^{\text {nd }}$ one operates \\
State 7 & 0 & 1 & 1 & $2^{\text {nd }}$ and $3^{\text {rd }}$ comps failed and $1^{\text {st }}$ one operates \\
State 8 & 1 & 1 & 1 & Three comps failed \\
\hline
\end{tabular}

\subsubsection{Transition Markov equation}

This part explains the transition case from state to other. State 1 represents the on case for all components and has three transitions by $\lambda 1, \lambda 2$, and $\lambda 3$ and each transition case can back to previous state by $\mu 1, \mu 2$, and $\mu 3$, respectively. States 2,3 , and 5 have two transitions by $\lambda 2, \lambda 3, \lambda 1, \lambda 3, \lambda 1$, and $\lambda 2$ respectively and each transition case can back to previous state by $\mu 2, \mu 3, \mu 1, \mu 3, \mu 1$, and $\mu 2$ respectively. States 4,6 , and 7 have one transition by $\lambda 3, \lambda 2$, and $\lambda 1$, respectively and each transition case can back to previous state by $\mu 3, \mu 2$, and $\mu 1$, respectively. State 8 represents the Off case for all components and hasn't any transition. The transition matrix can be established by states transition as shown in (8).

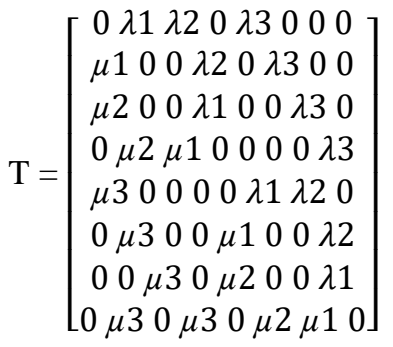

From the transition matrix it is noticed that, the dimensions of transition matrix are equal to $\mathrm{i}$ and $\mathrm{j}$ (both $\mathrm{i}$ and $\mathrm{j}$ equal to number of states). The changes in states are represented in the matrix by entering either the failure or repair rate which represent the transition from state to other. The matrix can be divided into three parts diagonal, upper diagonal, and lower diagonal. All elements in non-diagonal parts (when i is not equal to $j$ ) are represented by the transition from failure to repair rate, vice versa, and zero [3]. All elements in diagonal part (when $\mathrm{i}$ is equal to $\mathrm{j}$ ), are equal to one minus summation of the other elements in its row. Then the transition matrix changed as shown in (9) [3]. 


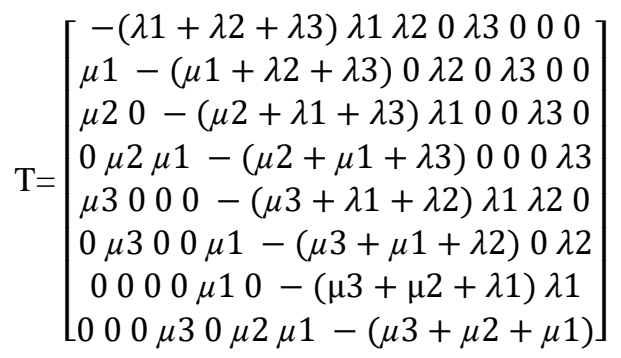

In (10) expresses the Markov equation [25].

$$
[P][T]=[0]
$$

Transpose the matrices are required and the equation changed to that form.

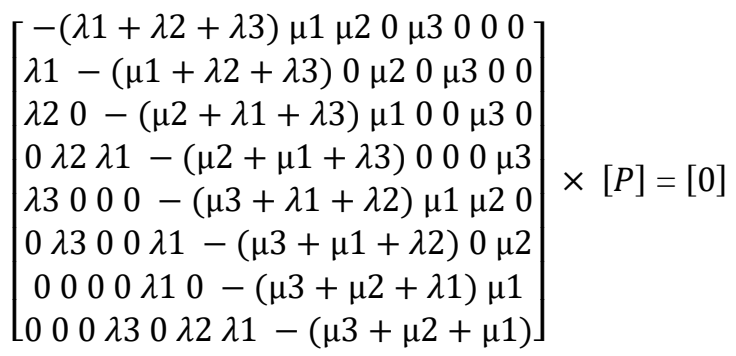

The sum of all individual probabilities is equal one as shown in (12) as Markov theory assumption. Based on that assumption, In (11) must be replaced to (13) [3].

$$
P 1+P 2+P 3+P 4+P 5+P 6+P 7+P 8=1
$$

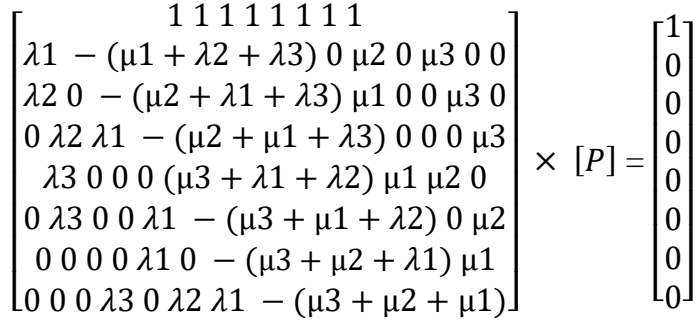

The independent probability values P1, P2, P3, P4, P5, P6, P7, and P8 can be determined by solving the equations. The probabilities classified into acceptable and unacceptable cases, all the values are acceptable except the last value P8 which represented the blackout of the whole system without considering islanding and this case is unacceptable case, therefore the availability of the system is calculated by (14) [5].

$$
\text { availability }=P 1+P 2+P 3+P 4+P 5+P 6+P 7
$$

The rate of departure between states can be calculated from transit matrix. The rate of departure of each frequency state is equal to the corresponding diagonal element of transit matrix with positive sign. The failure frequency and mean duration of states can be calculated from (15) and (16) [26].

$\mathrm{FFS}_{\mathrm{i}}=\mathrm{RDS}_{\mathrm{i}} * \mathrm{P}_{\mathrm{i}}$

$\mathrm{MDS}_{\mathrm{i}}=1 / \mathrm{RDS}_{\mathrm{i}}$

LOLP defined as the probability of the system load exceeding available generation capacity in the day and can be calculated in (17) [20].

$$
\operatorname{LOLP}=\sum_{\mathrm{i}=1}^{\mathrm{n}} \mathrm{P}_{\mathrm{i}} \mathrm{t}_{\mathrm{i}}
$$


Where: $t_{i}$ is the duration of loss of capacity in percent.

LOLE defined as the probability that aggregates will not be able to cover the necessary power consumption and can be calculated in (18) [20].

$$
\operatorname{LOLE}=\sum_{\mathrm{i}=1}^{\mathrm{n}} \mathrm{P}_{\mathrm{i}}\left(\mathrm{t}_{\mathrm{i}}-\mathrm{t}_{(\mathrm{i}-1)}\right)
$$

\subsection{Case study}

Figure 5 shows the IEEE electrical power system with 24 buses (IEEE_EPS_24_bus). IEEE_EPS_24_bus has 24 buses (10 buses have $138 \mathrm{KV}$ and 14 buses have $230 \mathrm{KV}$ ), 5 power transformer 230/138 KV, 9 cables, 29 transmission lines, and 10 generators [27]-[29]. The proposed technique studies the reliability of generation side for IEEE_EPS_24_bus. The blocks technique reduced the number of components from 32 generator units to 10 components. In case of 32 component's system, the number of probability states is equal to $2^{32}$ states. But the ten components system has $2^{10}=1024$ states. Zero one Markov matrix have inferred from the state probabilities. Each generator has number of generation units, each unit has power capacity tabulated in Table 2 [30]. The failure and repair rates for each generation unit listed in Table 3 [30]. All generation units are operating in case of state 1 and all of them are a failure in the last state. The transition matrix constructed from the zero one Markov matrix by transit the components in each state. In the final, 1024 probability case resulted by solving the Markov equation. The proposed technique and all tested cases are performed on a Lenovo laptop with processor Intel ${ }^{\circledR}$ core $^{\mathrm{TM}}$, i3-4030u, CPU@ $1.90 \mathrm{GHz}$, and installed memory (RAM) is equal to $4.00 \mathrm{~GB}$. All programs executed by MATLAB, R2015a with time taken about $8.458 \mathrm{sec}$. Figure 6 shown the flow chart of the proposed method.

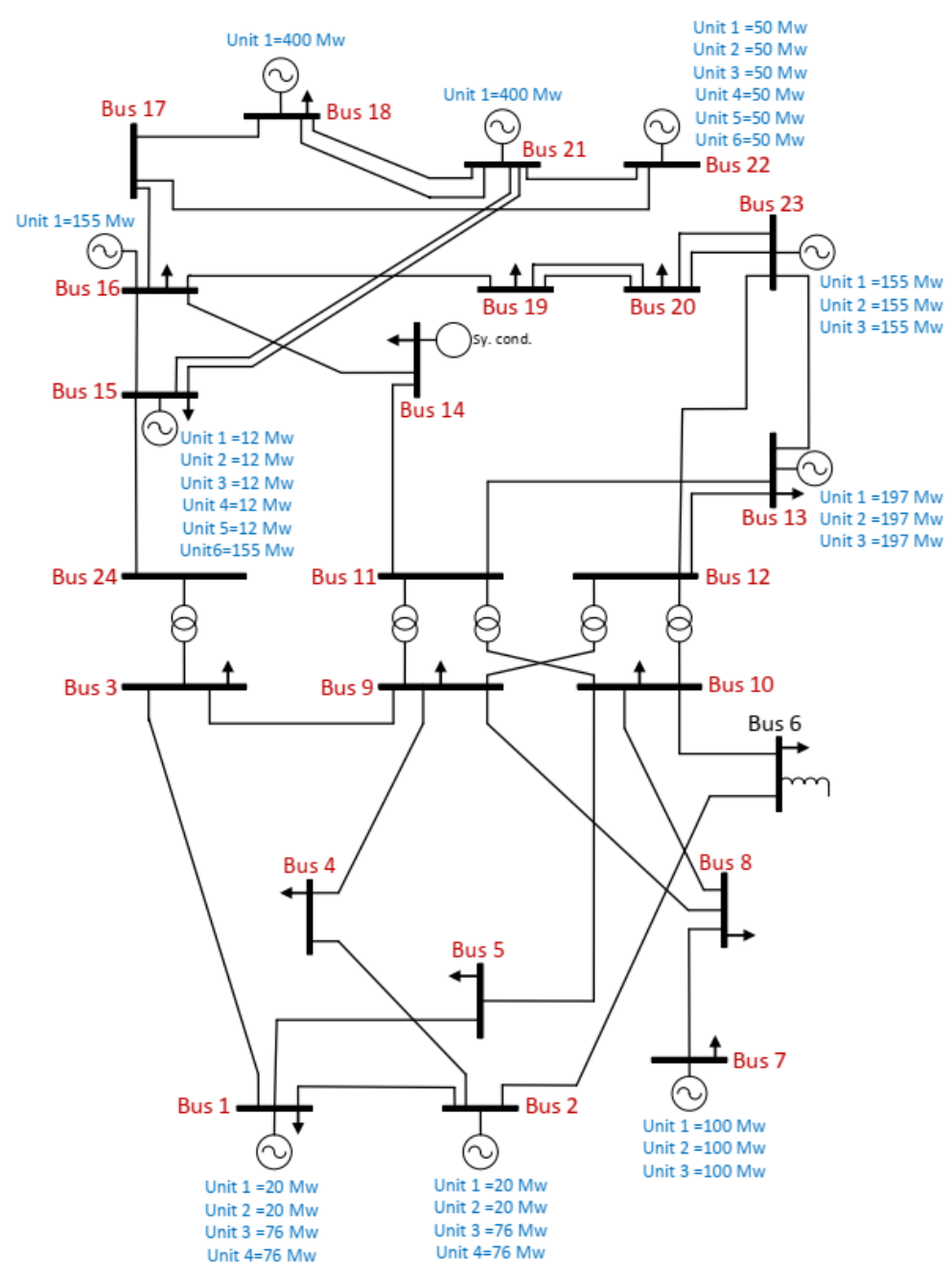

Figure 5. Single line diagram of IEEE_EPS_24 bus and generation unit data 
Table 2. Capacity and location of generation unit

\begin{tabular}{ccccccccccc}
\hline Bus No. & 1 & 2 & 7 & 13 & 15 & 16 & 18 & 21 & 22 & 23 \\
\hline & 20 & 20 & 100 & 197 & 12 & 155 & 400 & 400 & 50 & 155 \\
& 20 & 20 & 100 & 197 & 12 & - & - & - & 50 & 155 \\
& 76 & 76 & 100 & 197 & 12 & - & - & - & 50 & 350 \\
& 76 & 76 & - & - & 12 & - & - & - & 50 & - \\
Total capacity & - & - & - & - & 12 & - & - & - & 50 & - \\
& - & - & - & - & 155 & - & - & - & 50 & - \\
& 192 & 300 & 591 & 215 & 155 & 400 & 400 & 300 & 660 \\
\hline
\end{tabular}

Table 3. Failure and repair rate for generation unit [29]

\begin{tabular}{ccccccccc}
\hline $\begin{array}{c}\text { Generation } \\
\text { unit capacity }\end{array}$ & $\lambda$ & $\mu$ & $\begin{array}{c}\text { Generation unit } \\
\text { capacity }\end{array}$ & $\lambda$ & $\mu$ & $\begin{array}{c}\text { Generation unit } \\
\text { capacity }\end{array}$ & $\lambda$ & $\mu$ \\
\hline 12 & $0.34 \mathrm{e}^{-3}$ & 0.0166 & 76 & $0.51 \mathrm{e}^{-3}$ & 0.025 & 197 & $0.105 \mathrm{e}^{-2}$ & 0.02 \\
20 & $0.222 \mathrm{e}^{-2}$ & 0.02 & 100 & $0.833 \mathrm{e}^{-3}$ & 0.02 & 350 & $0.87 \mathrm{e}^{-3}$ & 0.01 \\
50 & $0.505 \mathrm{e}^{-3}$ & 0.05 & 155 & $0.104 \mathrm{e}^{-2}$ & 0.025 & 400 & $0.909 \mathrm{e}^{-3}$ & 0.00667 \\
\hline
\end{tabular}

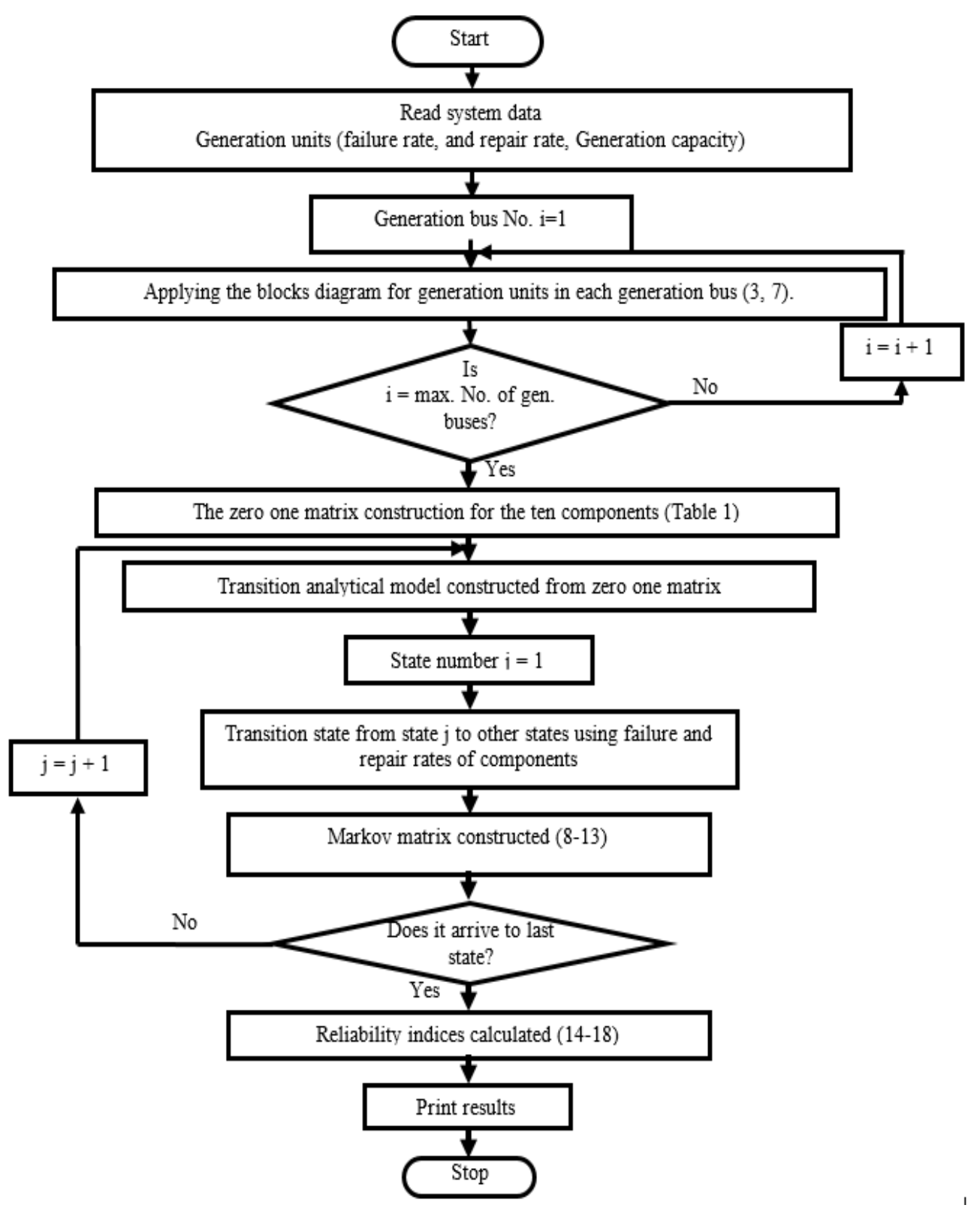

Figure 6. The flow chart of the proposed method 


\section{RESULTS AND DISCUSSION}

The failure probability values of states are shown in the Figures 7 and 8 . The probability values for state 2 to state 35 are shown in Figure 7 and the probability values for state 36 to state 1024 are shown in Figure 8. It is noticed from the figures that, the max. and min. failure probability values are equal to 0.722501275 at state No. 1 and $7.06776 \mathrm{e}^{-22}$ at state No. 1024 , respectively. All connected generators at buses are in operating mode in case of state 1 .

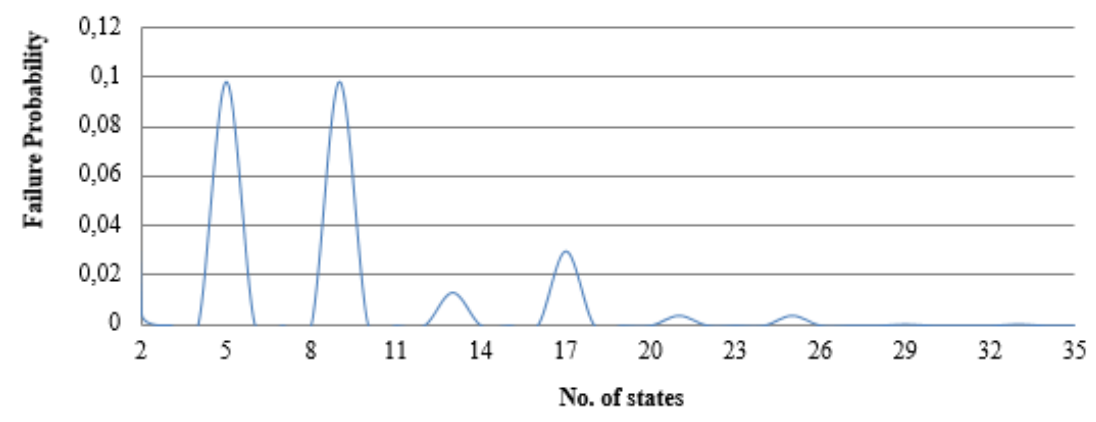

Figure 7. Failure probability value for states from 2 to 35 states

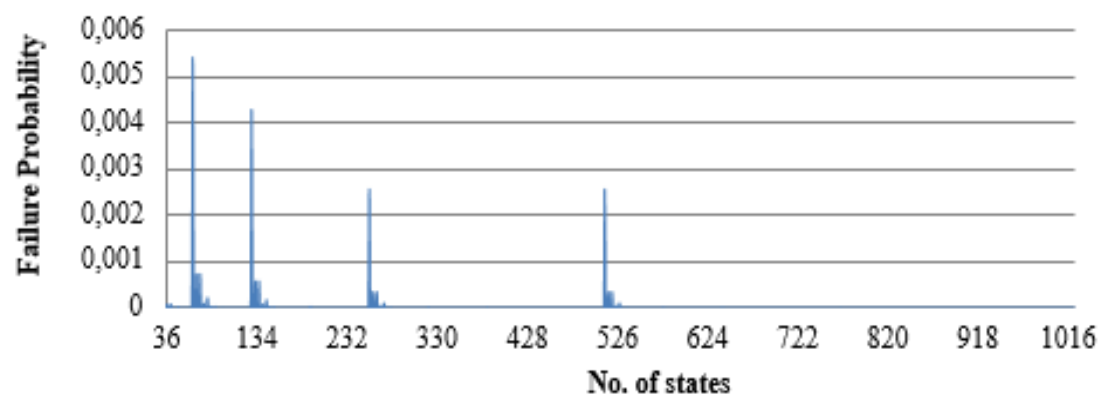

Figure 8. probability value for states from 36 to 1024 states

All connected generators at buses are in failure mode in case of state 1024. Figure 9 shows the probability of generation capacity state which get out of service for each state of failure and also shows the probability of generation capacity state which remained in service for each probability state of failure. It is noticed from Figure 9 that, probability state 1 has complete generation capacity $(3405 \mathrm{MW})$ and no any failure, probability state 1024 has completely black out and all generation buses failure. Other probability states have some buses in service and some other buses out of service or failure. The probability of the margin state can be gotten by multiply this probability capacity state and probability load state probabilities [20].

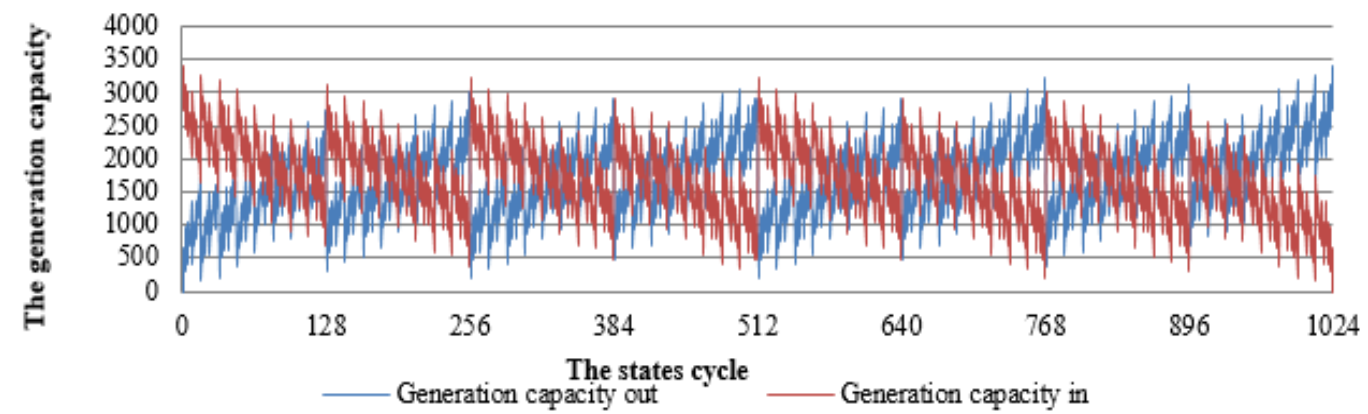

Figure 9. Probability of generation capacity state in and out of service 
The probability and availability of each generation bus shown in Figure 10. From the figure, it is found that, the max. and min. generation bus probabilities are equal to 0.108666 at bus 13 and 0.000127 at bus 3 , respectively, and max. and min. bus generation availability are equal to 0.999873 at bus 3 and 0.891334 at bus 13 , respectively.

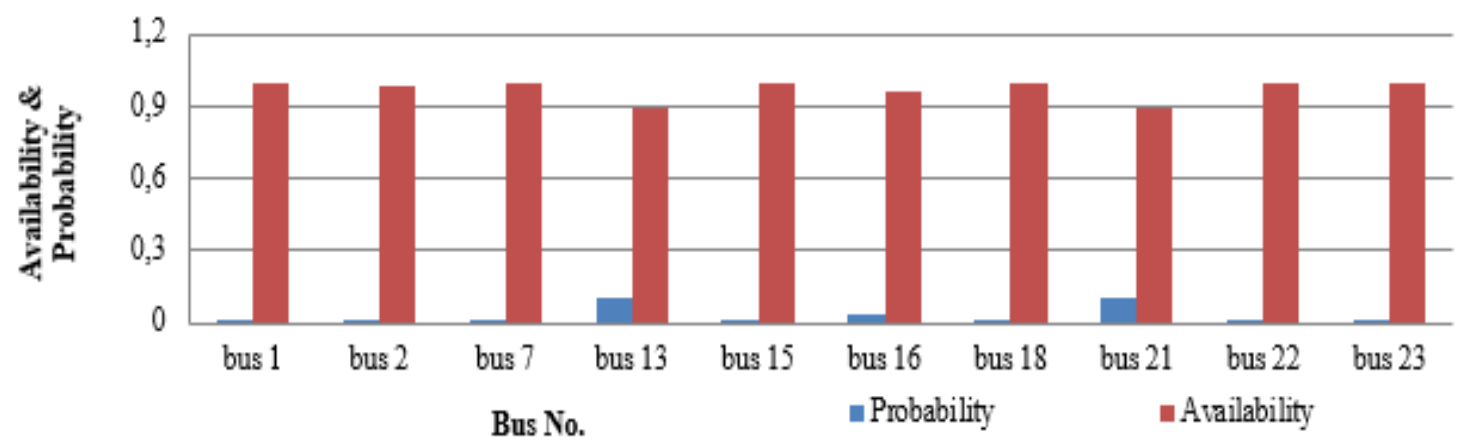

Figure 10. Failure probability and availability value for generations connected to the buse

The total probability states are 1024 state, all of them are acceptable except state number 1024 which it has all connected generators at buses in failure mode. The unacceptable state has probability value equal to $7.07 \mathrm{e}^{-22}$. The availability for whole generation system is the probability state $\mathrm{P} 1$ which is equal to 0.7225. The failure frequency of the states is shown in the Figure 11. The figure shows the failure frequency for the states from 2 to 1024 state. From the figure, it is noticed that, the max. failure frequency and corresponding duration are equal to 0.003564 and 202.747 at P1, respectively. The min. failure frequency and corresponding duration are equal to $5.701 \mathrm{e}^{-22}$ and 1.2397 at $\mathrm{P} 1024$, respectively.

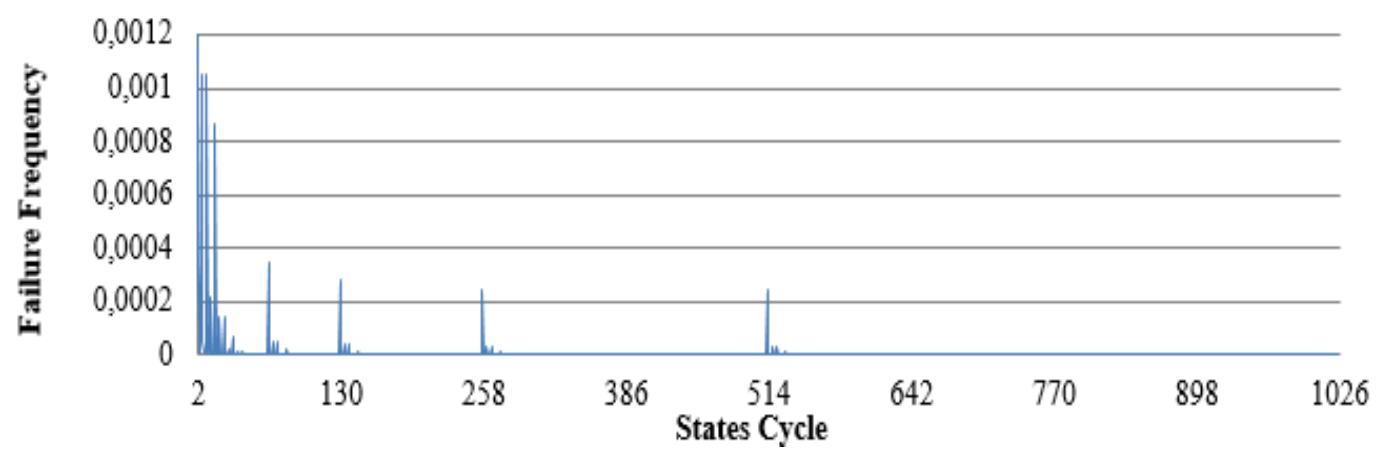

Figure 11. Failure frequency for states from 2 to 1024 states

The proposed technique calculated the reliability indices for the whole system which are shown in Table 4. It is noticed from the table that; the whole system failure rate is equal to $3.57 \mathrm{e}^{-05}$. The reliability of whole system is calculated by the proposed method and equal to 0.7316. The LOLP and LOLE indices are equal to 2.02523 and 19.0268 , respectively. The average frequency and interruption durations are calculated and equal to 0.00932 and 0.9381 , respectively. The total interruption duration assessed and found equal to 3642.4 Hrs which represents the total interruption time during a year.

Table 4. The calculated reliability indices for system

\begin{tabular}{cccc}
\hline The index & value & The index & Value \\
\hline Average frequency duration [13] & 0.00932 & System reliability & 0.7316 \\
Total interruption duration (hours) & 3642.4 & LOLP [20] & 2.0252 \\
Average interruption duration (hours) [13] & 0.9381 & LOLE [20] & 19.0268 \\
\hline
\end{tabular}




\section{CONCLUSION}

The proposed technique focuses on the probability, availability, and reliability analysis for generation system which has very large number of generators. The IEEE_EPS_24_bus has a total generation unit reach to 32 unit. It is very difficult to assess the probability, availability, and reliability by Markov technique for whole system which has all of these components. The combination between the block diagram and Markov techniques overcomes on the problem. The block diagram technique reduced the number of components from 32 units to only 10 units and Markov technique assesses the reliability of ten components' system faster and accurate. The proposed method has been succeeded to assess the generation system reliability and obtain the value of generation system reliability for IEEE_EPS_24_bus. The maximum frequency and mean duration of states are equal to 0.003564 at state No. 1 and 202.7467 at state No. 1, respectively. The minimum frequency and mean duration of states are equal to $5.7 \mathrm{e}^{-22}$ at state No. 1024 and 1.2397 at state No. 1024, respectively. From the max. and min. values of frequency and duration of the states, it can conclude that, the max values of frequency and duration are in P1 which represents available case and in which all generation buses are in operation mode. The min values of frequency and duration are in P1024 which represents unacceptable case and in which all generation buses are in failure mode. Many factors effect on the frequency and duration like failure rate values, repair rate values for each component, and arrangement of states. The system reliability assessed by the proposed technique and found equal to 0.7316 . The system reliability indices like average interruption duration, average frequency duration, total interruption duration, LOLP, and LOLE are calculated and found equal to 0.00932, 0.9381, 3642.4, 2.0252, and 19.0268. The total interruption duration value seems high value and must be improved by improved the repair rates of the system components, reduced the failure rates of system components, and recovered the interrupted area by restoration supply like renewable generation.

\section{REFERENCES}

[1] A. Ehsani, A. M. Ranjbar, A. Jafari, and M. F.- Firuzabad, "Reliability evaluation of deregulated electric power systems for planning applications," reliability engineering \& system safety, vol. 93, no. 10, pp. 1473-1484, 2008, doi: 10.1016/j.ress.2007.10.005.

[2] R. Billintonz and R. N. Allan, "Reliability of electric power systems: an overview," in: pham h. (Eds) handbook of reliability engineering, springer, London, 2003, pp. 511-528, doi: 10.1007/1-85233-841-5_28.

[3] B. Boussahoua and A. Elmaouhab, "Reliability Analysis of Electrical Power System Using Graph Theory and Reliability Block Diagram," 2019 Algerian Large Electrical Network Conference (CAGRE), Algiers, Algeria, 2019, pp. 1-6, doi: 10.1109/CAGRE.2019.8713175.

[4] V. S. K. Babu, Madhusudan, and V. Ganesh, "Probabilistic performance index base contingency screening for composite power system reliability evaluation," International Journal of Electrical and Computer Engineering (IJECE), vol. 8, no. 5, pp. 2661-2670, 2018, doi: 10.11591/ijece.v8i5.pp.2661-2670.

[5] A. Abdulkarim, N. Faruk, A. O. Oloyede, and O. Abiodun, "Reliability study of stand-alone hybrid renewable energy microgrids," Iranian journal of science and technology, transactions of electrical engineering, vol. 43, no. 1, pp. 411-425, 2019, doi: 10.1007/s40998-018-0119-8.

[6] V. Khare, S. Nema, and P. Baredar, "Reliability analysis of hybrid renewable energy system by fault tree analysis," energy \& environment, vol. 30, no. 3, pp. 542-555, 2019, doi: 10.1177/0958305X18802765.

[7] N. A. Shalash, A. Z. Ahmad, and A. Jaber, "Multi-agent approach to reliability assessment of power system generation using fuzzy logic, ” International journal of simulation-systems, science \& technology, vol. 17, no. 26, pp. 18.1-18.9, October 2016, doi: 10.5013/IJSSST.a.17.32.18.

[8] T. Adefarati and R. C. Bansal, "Reliability, economic and environmental analysis of a microgrid system in the presence of renewable energy resources," Applied Energy, vol. 236, pp. 1089-1114, 2019, doi: 10.1016/j.apenergy.2018.12.050.

[9] A. Bourezg and H. Meglouli, "Reliability assessment of power distribution systems using disjoint path-set algorithm," Journal of industrial engineering international, vol. 11, no. 1, pp 45-57, Mar. 2015, doi: 10.1007/s40092-014-0083-5.

[10] Kunaifi and A. Reinders, "Perceived and reported reliability of the electricity supply at three urban locations in Indonesia," Energies, MDPI, vol. 11, no. 1, 2018, Art. no. 140, doi: 10.3390/en11010140.

[11] E. H. Joseph, K. H. LaCommare, H. C. Caswell, and D. Till, "Distribution system versus bulk power system: identifying the source of electric service interruptions in the US," IET generation, transmission \& distribution, vol. 13, no. 5, pp. 717-723, Feb. 2019, doi: 10.1049/iet-gtd.2018.6452.

[12] M. Ghiasi, N. Ghadimi, and E. Ahmadinia, "An analytical methodology for reliability assessment and failure analysis in distributed power system," SN Applied Sciences, vol. 1, no. 1, Jan. 2019, Art. no. 44, doi: $10.1007 / \mathrm{s} 42452-018-0049-0$.

[13] M. Almuhamaini and A. Al-Sakkaf, "Markovian model for reliability assessment of microgrids considering load transfer restriction," Turkish journal of electrical engineering \& computer sciences, vol. 25, no. 6, pp. 4657-4672, 2017, doi: 10.3906/elk-1609-137.

[14] Y. Liu and C. Singh, "Reliability Evaluation of Composite Power Systems Using Markov Cut-Set Method," in IEEE Transactions on Power Systems, vol. 25, no. 2, pp. 777-785, May 2010, doi: 10.1109/TPWRS.2009.2033802. 
[15] A. Thompson, B. Kazemtabrizi, C. J. Crabtree, C. Dao, F. Dinmohamadi, and D. Flynn, "Reliability and economic evaluation of high voltage direct current interconnectors for large-scale renewable energy integration and transmission," $15^{\text {th }}$ IET international conference on AC and DC power transmission (ACDC 2019), Coventry, UK, vol. 10, no. 6, 2019, pp. 1-7, doi: 10.1049/cp.2019.0010.

[16] Y. Ren et al., "A reliability evaluation method for radial multi-microgrid systems considering distribution network transmission capacity," Computers and Industrial Engineering, vol. 139, 2020, Art. no. 106145, doi: 10.1016/j.cie.2019.106145.

[17] S. S. Raghuwanshi and R. Arya, "Reliability evaluation of stand-alone hybrid photovoltaic energy system for rural healthcare centre," Sustainable Energy Technologies and Assessments, vol. 37, 2020, Art. no. 100624, doi: 10.1016/j.seta.2019.100624.

[18] T. T. Pham, T.-Chi Kuo, and D. M. Bui, "Reliability evaluation of an aggregate battery energy storage system in microgrids under dynamic operation," International Journal of Electrical Power and Energy Systems, vol. 118, 2020, Art. no. 105786, doi: 10.1016/j.ijepes.2019.105786.

[19] R. A. Bakkiyara and N. Kumarappan, "Particle swarm optimization based optimal reliability design of composite electric power system using non-sequential Monte Carlo sampling and generalized regression neural network," International conference on swarm, evolutionary, and memetic computing SEMCCO 2013, Springer, Cham, vol. 8297, 2013, pp. 580-589, doi: 10.1007/978-3-319-03753-0_52.

[20] M. Čepin "Assessment of power system reliability methods and applications," Springer Science and Business Media, Jul. 2011.

[21] G. Muñoz-Delgado, J. Contreras and J. M. Arroyo, "Reliability Assessment for Distribution Optimization Models: A Non-Simulation-Based Linear Programming Approach," in IEEE Transactions on Smart Grid, vol. 9, no. 4, pp. 3048-3059, Jul. 2018, doi: 10.1109/TSG.2016.2624898.

[22] S. M. M. Aval and A. Ahadi, "Reliability evaluation of wind turbine systems' components," Bulletin of electrical engineering and informatics (BEEI), vol. 5, no. 2, pp. 160-168, 2016, doi: 10.11591/eei.v5i2.525.

[23] S. S. Sarma, V. Madhusudhan, and V. Ganesh, "Reliability worth assessment of active distribution system considering protective devices and multiple distributed generation units," International Journal of Applied Power Engineering (IJAPE), vol. 7, no. 2, pp. 111-119, 2018, doi: 10.11591/ijape.v7.i2.pp111-119.

[24] M. M. Othman, M. A. N. M. Jamaluddin, F. Fauzi, and I. Musirin, "Improved reliability assessment of backup battery storage integrated with power supply system in a building," International Journal of Power Electronics and drive system (IJPEDS), vol. 10, no. 3, pp. 1538-1546, 2019, doi: 10.11591/ijpeds.v10.i3.pp1538-1546.

[25] J. F. L. van Casteren, M. H. J. Bollen and M. E. Schmieg, "Reliability assessment in electrical power systems: the Weibull-Markov stochastic model," in IEEE Transactions on Industry Applications, vol. 36, no. 3, pp. 911-915, May-Jun. 2000, doi: 10.1109/28.845070.

[26] V. Dharwd and S. B. Karjagi, "Modeling and analysis of generation system based on markov process with case study," International Journal for Innovative Research in Science and Technology, vol. 1, no. 11, pp. 539-545, Apr. 2015.

[27] C. Ordoudis, P. Pierre, M. Gonzalez, J. Miguel, and Z. Marco, “An updated version of the ieee 24-bus system for electricity market and power system operation studies," Technical university of Denmark, pp. 0885-8950, 2016.

[28] R. Billinton and R. N. Allan, "Reliability assessment of large electric power systems," Springer, 2012.

[29] P. M. Subcommittee, "IEEE Reliability Test System," in IEEE Transactions on Power Apparatus and Systems, vol. PAS-98, no. 6, pp. 2047-2054, Nov. 1979, doi: 10.1109/TPAS.1979.319398.

[30] H. Kim and C. Singh, "Composite power system reliability modeling and evaluation considering aging components," 2009 International Conference on Electrical and Electronics Engineering - ELECO 2009, Bursa, Turkey, 2009, pp. I-14-I-18, doi: 10.1109/ELECO.2009.5354997.

\section{BIOGRAPHIES OF AUTHORS}

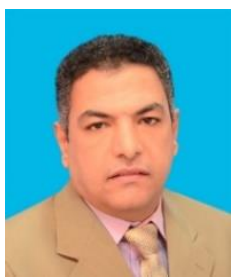

Aiman Abd Elkader Tawfiq was born in El Sharkia, Egypt, in 1973. He got the B. Sc. Degree in electric power and machines in 1997 from Faculty of Engineering, Zagazig university, Zagazig, Egypt and the M. Sc. in 2018 from Faculty of Engineering, Zagazig university. He is currently a member in electrical power department, vocational training institute, the public authority for applied education and training, Kuwait. He is pursuing his doctor of philosophy studies with Faculty of Engineering, Zagazig university. His research interests are in antlion optimizer, Particle Swarm Optimization, distributed generation, radial distribution systems, renewable energy, radial distribution reconfiguration, block diagram, Markov process, and power system reliability assessment.

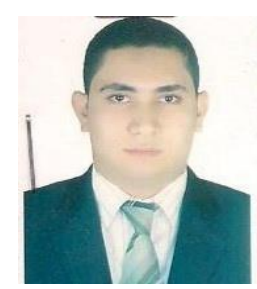

Mohamed Osama Abd el-Raouf was born in Benha-Egypt, on June 27, 1991. He graduated from the Shoubra Faculty of Engineering-Benha University. He earned his BSc, MSc, PHD of Electrical Power Engineering at Shoubra Faculty of Engineering, Benha University, 2013, 2016, 2019 respectively. He worked as an Instructor in Thebes's Academy (Thebes Higher Institute of Engineering) for two years currently, he is Researcher in the Building Physics and Environmental Research Institute, Housing and Building National Research (HBRC), Cairo, Egypt. His research interests include renewable energy systems and energy saving in buildings. 


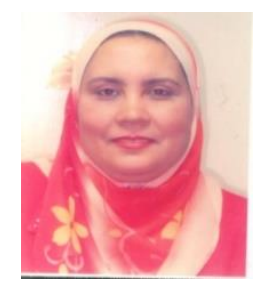

A. A. El-Gawad was born in Aswan, Egypt, in 1971. She got the B. Sc. Degree from the Faculty of Engineering, Zagazig University, Egypt, in 1993, the M. Sc. Degree from the Faculty of Engineering, Zagazig University, Egypt, in 1996, and the Ph. D. degree from the Faculty of Engineering, Zagazig University, Egypt, in 2002. She was a Professor of the Electrical Power and Machines Department, Faculty of Engineering, Zagazig University, Egypt. She is currently vice dean of faculty of computer \& information, Zagazig University, Zagazig, Egypt. Her research interests include electrical power systems protection using artificial intelligence "AI" (expert systems - neural networks- wavelet analysis), load flow studies, load forecasting studies, power quality studies (harmonics-power factor-Flicker), FACTS, renewable energy (wind energy), and material \& nano applications in electrical power system.

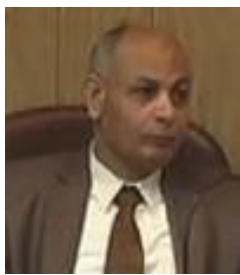

M. A. Farahat was born in El Sharkia, Egypt, in 1959. He received the B. Sc. Degree from the Faculty of Engineering, Al-Azhar University, Egypt, in 1983, the M. Sc. Degree from the Faculty of Engineering, Menofia University, Egypt, in 1991, and the Ph. D. degree from the Faculty of Engineering, Zagazig University, Egypt, with the Scholarship Channel System, Hannover University, Germany, in 1996. He is a Professor of the Electrical Power and Machines Department, Faculty of Engineering, Zagazig University, Egypt. His research interests include different types of renewable energy, load forecasting, and distribution systems. 